\title{
A Confirmatory Factor Analysis on Reading Constructs across Ages
}

\author{
Ae Hwa Kim, Ui Jung Kim ${ }^{\text {b }}$, Eun Young Kang ${ }^{c}$ \\ ${ }^{a}$ Department of Special Education, Dankook University, Yongin, Korea \\ ${ }^{b}$ Department of Special Education, Korea Nazarene University, Cheonan, Korea \\ 'Graduate School of Education, Yongin University, Yongin, Korea
}

Correspondence: Ui Jung Kim, PhD Department of Special Education, Korea Nazarene University, 48 Wolbong-ro, Seobuk-gu, Cheonan 31172, Korea

Tel: +82-41-570-7838

Fax: +82-41-570-7839

E-mail: uijungkim@kornu.ac.kr

Received: October 5, 2016

Revised: November 9, 2016

Accepted: November 23, 2016

\begin{abstract}
Objectives: Our major goal in this study was to figure out a factor structure of reading as a construct. We were especially interested in how comparable the results would be across ages (grades). Methods: To find out how reading constructs change with increasing age, we used two confirmatory factor analyses (CFA) across ages (grades) using word recognition, reading fluency, and reading comprehension, which are generally understood as the three main factors of reading constructs. Results: The CFA targeted a whole participant regardless of age (grade); a three-factor reading construct model (separate word recognition, reading fluency, reading comprehension) represented the best fit. However, a two-factor reading construct model (word recognition and reading fluency combined, reading comprehension separate) showed the best fit at the preschool stage while the three-factor model was the best fit for the elementary level (grade 1 to grade 6). Conclusion: According to the results, different reading constructs should be considered in preschool and in elementary school. Also, reading fluency should be a distinct factor within reading constructs in first grade.
\end{abstract}

Keywords: Word recognition, Reading fluency, Reading comprehension, Confirmatory factor analysis, Reading structure
지난 수십 년간 복잡한 인지적인 과정이 요구되는 읽기(reading) 를 이해해보고자 하는 많은 노력들이 있어 왔으며, 읽기 구조(reading construct)에 대한 연구도 이러한 노력의 일환으로 실시되었다. 읽기 구조를 탐색한 초기의 많은 선행연구들에서는 단어인지(word recognition)와 읽기이해(reading comprehension)를 읽기 구조를 구성하는 대표적인 두 개의 하위 요인이라고 설명하였다(예: Carr \& Levy, 1990; Gough \& Tunmer, 1986). 이 당시, 읽기유창성(reading fluency)의 어려움은 비효과적인 음운처리로 인한 음독 및 단 어인지 문제에 그 원인이 있다고 여겼다(Lyon \& Moats, 1997). 따라 서 읽기 구조에 대한 초기 연구들에서는 '유창성'을 단어인지의 자 동화(automaticity)로 보고, 유창성이 단어인지 요인에 포함되는 것 으로 간주하였다(Gough, 2002; Hoover \& Gough, 1990).

이와 같이 읽기 구조에 대한 초기 연구들에서 주목한 '유창성'은 단어인지의 자동화를 강조한 개별 단어 수준에서의 유창성이었다.
그에 비해 National Reading Panel (2000) 등의 보고서가 발표된 2000년대를 전후로 하여 강조된 '유창성'의 개념은 글(text) 수준에 서의 유창성으로, 개별 단어 수준에서의 유창성과는 차별화되었 다. 이들 간의 차이점을 살펴보면, 유창성을 어떻게 조작적으로 정 의하고 어떤 수준에서의 유창성에 초점을 맞추느냐에 따라 두 가 지 유형의 유창성으로 나뉘는 것을 알 수 있다. 첫째, 개별 단어 수 준에서의 유창성은 ‘효율적인 단어인지’(efficient word recognition), 즉 단어를 빠르게, 정확하게 읽는 것(Gough \& Tunmer, 1986)에 초 점을 맞춘 ‘유창성’ 개념이다(Gough, 2002). 둘째, 글 수준에서의 유창성은 글을 읽을 때의 '속도, 정확성, 적절한 표현'으로 정의하면 서, 글 수준에서의 초점을 맞춘 ‘유창성’ 개념이다(National Reading Panel, 2000). 개별 단어 수준의 유창성과 글 수준에서의 유창 성은 빠르고 정확하게 읽는 것(즉, 정확성과 속도)이라는 공통적인 특징을 지닌다. 하지만, 첫 번째 유형의 유창성은 개별 단어 읽기의 
정확성과 속도로 '효율적인 단어인지'(efficient word recognition) 또는 '단어인지의 자동화'(automaticity)이고, 두 번째 유형의 유창 성은 글 읽기의 속도와 정확성을 의미하며 '읽기유창성'(reading fluency)를 의미한다는 측면에서 차별화 된다. 여러 연구들에 따르 면, 개별 단어를 유창하게 읽는 단어인지 유창성과 글을 유창하게 읽는 읽기유창성은 서로 구분되는 요인임이 보고되었다(Berninger, Abbott, Billingsley, \& Nagy, 2001; Breznitz, 2006; Fuchs, Fuchs, Hosp, \& Jenkins, 2001; Wolf \& Katzir-Cohen, 2001). 또한 National Reading Panel (2000) 등의 보고서에 강조한 유창성의 개념은 글 수준에서의 읽기유창성으로, 읽기유창성이 읽기의 궁극적인 목적 인 읽기이해에 중요한 영향을 미친다는 점에 주목하였다.

이와 같이 글 수준에서의 읽기유창성의 개념이 강조되면서, 기존 의 읽기 구조(단어인지와 읽기이해로 구성된 읽기 구조)에 대한 의 문이 제기되었다. 이에 일련의 연구들에서 읽기유창성이 단어인지 와 읽기이해 이외에 읽기의 구조를 구성하는 독립적인 하위 요인인 지를 살펴보는 연구들이 발표되었으며, 더 나아가 학년에 따라 읽 기의 구조가 차별적으로 나타나는지에 주목하였다. Geva와 Farnia (2012)는 초등학교 2학년과 5학년을 대상으로 실시한 연구에서 초등학교 2학년 학생에게는 단어인지와 읽기유창성이 단일 요인으 로 나타났지만, 5 학년 학생에게는 단어인지와 읽기유창성이 구분 되는 요인으로 나타났다고 보고하였다. 이와 비슷하게 Wood (2006) 는 초등학교 3학년과 4학년을 대상으로 실시한 연구에서 초등학교 3 학년의 경우 읽기유창성과 읽기이해가 유의한 관련성을 지니지 않는 것으로 나타난 반면, 초등학교 4 학년의 경우에는 읽기유창성 과 읽기이해가 유의한 관련성을 지니는 것으로 나타났다. 이러한 결과를 지적하면서 Wood (2006)는 향후 읽기유창성과 읽기이해 의 관련성이 읽기 발달 단계에 따라 어떠한 양상으로 나타나는지 를 연구할 필요가 있음을 제안하였다. 또한 Tilstra, McMaster, Van den Broek, Kendeou와 Rapp (2009)은 4학년, 7학년, 9학년을 대상 으로 실시한 연구에서 모든 학년에서 읽기유창성이 단어인지와는 별도로 읽기이해와 유의한 관련성을 지녔음을 보고하면서, 단어인 지와 읽기이해로 구성된 기존의 읽기 구조의 한계점을 지적하였다.

이상의 선행연구들을 살펴보면, 초등학교 저학년에는 읽기유창 성이 읽기 구조를 구성하는 독립적인 요인으로 나타나지 않지만, 초등학교 고학년에는 읽기유창성이 독립적인 요인으로 나타나는 것을 알 수 있다. 즉, 초등학교 저학년 때는 단어인지와 읽기유창성 이 단일 요인으로 나타나다가, 초등학교 고학년으로 올라가면서 단 어인지와 읽기유창성이 두 개의 별개 요인으로 나뉘면서 읽기유창 성 역시 제 3 의 별개 하위 요인으로서의 유의한 설명량을 가지고 있 음이 확인된 바 있다. 초등학교 고학년이 되면 읽기유창성이 독립
적인 요인으로 분화되는 결과에 대한 이론적 근거는 Chall (1983) 이 제안한 읽기 발달 단계에서 찾아볼 수 있다. Chall (1983)이 제안 한 6단계 읽기 발달을 살펴보면 다음과 같다. 첫째, 태어나서부터 6 세까지의 읽기 전 단계(stage 0)에서는 책에 대한 경험을 통해 몇몇 주변 단어를 통단어로 획득하게 된다. 둘째, 초등학교 1학년 2학년 의 경우는 초기 읽기 단계(stage 1)이며, 낱자의 소리와 철자 체계에 대한 학습을 하는 시기이다. 셋째, 초등학교 2학년 3학년에 해당하 는 2단계(stage 2)는 단어 읽기의 유창성을 발달시키는 시기이다. 넷 째, 4학년부터 중학교까지에 해당하는 3단계(stage 3)는 '읽기를 위 한 학습’에서 '학습하기 위한 읽기’로의 전환이 일어나는 시기이다. 다섯째, 4단계(stage 4)와 5단계(stage 5)는 각각 고등학교 시기와 성 인기로 다양한 목적에 맞는 다양한 읽기를 하는 시기이다.

Chall (1983)이 제안한 읽기 발달 단계를 살펴보면, 초등학교 취 학 전 기간인 stage 0 부터 stage 2 까지는 개별 단어 '읽기의 학습'과 자동화에 초점이 맞추어진 단계라고 할 수 있다. 그에 비해 초등학 교 4학년을 기점으로 시작되는 stage 3 부터는 개별 단어 읽기의 학 습이 아닌, '학습을 위한 읽기'가 시작되는 단계이며, 학습을 위한 읽기를 수행하기 위해서는 '글'을 유창하게 읽는 능력이 요구되는 시기라고 할 수 있다. 이와 관련하여 Silverman, Speech, Harring과 Ritchey (2013)는 초등학교 고학년이 시작되는 4학년을 기점으로 많은 학생들이 읽기에 어려움을 나타내는 것과 관련하여, 이 시기 부터는 단어인지와 읽기이해만으로 이들의 읽기에 대한 어려움을 설명하는 것은 불충분하다는 점을 강조하면서, 읽기유창성이 별개 의 요인으로 고려되어야함을 주장하였다. 따라서 국내에서도 읽기 발달 단계에 따라 읽기 구조가 차별적으로 나타나는지(즉, 읽기 발 달 단계에 따라 단어인지, 읽기유창성, 읽기이해가 읽기 구조를 구 성하는 독립적인 요인이라는 차별적 특징이 존재하는지)를 살펴보 는 것은 의의가 있다고 할 수 있다.

국내의 경우, 읽기유창성과 읽기이해와의 관련성을 살펴본 연구 는 수 편 보고된 바 있지만(Kim, Kim, Yoo, \& Hwang, 2011; Lee \& $\mathrm{Kim}, 2003)$, 읽기유창성이 읽기 구조를 구성하는 독립적인 요인인 지, 더 나아가서 읽기의 하위 요인 구조는 읽기 발달 단계에 따라 어 떠한 양상으로 나타는지를 직접적으로 살펴본 연구는 발표된 바가 없다. 위에서 언급한 국외 선행문헌에서와 비슷하게 읽기 발달 단 계에 따라 읽기유창성이 분화되는지, 그리고 읽기유창성이 독립적 인 요인으로 분화되는 시점이 국외에서와 비슷한 시기인지 등을 살 펴본 연구는 이루어지지 않았다. 한글은 일반적으로 표층표기체계 언어권에 속하는 것으로 평가되고(Seymour, Aro, \& Erskine, 2003), 표층표기체계 언어권에서는 단어인지 정확성이 초등학교 저학년 때 이미 천정효과를 나타낸다고 보고된 바 있다(Cossu, Giuliotta, 
\& Marshall, 1995; Landerl \& Wimmer, 2008). 따라서 표층표기체 계 언어권에 속하는 한글을 사용하는 아동을 대상으로 연령에 따 른 읽기 구조를 살펴보는 것은 의의가 있는 일이라고 하겠다. 따라 서 본 연구에서는 읽기 발달이 시작되는 만 5세 아동부터 초등학교 6학년 학생을 대상으로 읽기 구조를 살펴봄으로써, 읽기 발달 단계 에 따른 읽기 구조가 연령이 증가하면서 얼마나 일관성 있게 또는 차별적으로 나타나는지를 살펴보고자 하였다. 본 연구에서 만 5세 아동부터 연구대상에 포함한 이유는 다음과같다. 최근 발표된 $\mathrm{Kim}$ 과 $\operatorname{Kim}$ (2015)의 연구에서 만 5세 아동의 단어인지 정확도는 평균 약 $10 \%$ (범위: $1 \%-20 \%$ ), 만 6세 아동의 단어인지 정확도는 약 $70 \%$ (범위: 40\%-91\%)로 나타났다. 이러한 데이터에 따르면, 국내 아동 들은 만 5 세부터 단어 읽기 성취도가 발달되기 시작하는 것으로 보 는 것이 적절한 것으로 판단하여 만 5 세부터 연구 대상에 포함하여 연구를 실시하였다. 따라서 본 연구에서는 한글을 사용하는 국내 아동들을 대상으로 읽기 구조가 어떠한지를 살펴보고, 더 나아가 읽기 구조가 읽기 발달 단계에 따라 어떠한 양상을 보이는지를 살 펴보고자 하였다. 본 연구의 구체적인 연구문제는 다음과 같다.

연구문제 1. 읽기유창성은 단어인지, 읽기이해와 구분되어 읽기 구조를 설명하는 별개의 하위 요인인가?

연구문제 2. 읽기 구조는 연령별(학년별)로 어떠한 양상을 보이 는가?

\section{연구 방법}

\section{검사 대상}

본 연구에는 여섯 개의 유치원 및 세 개의 초등학교에 재학 중인 만 5세부터 초등학교 6학년까지 총 522명의 학생들이 참여하였다. 만 5세 학생 32명, 만 6세 학생 45명이 참여하였고, 1학년 72명, 2학 년 70명, 3학년 80명, 4학년 70명, 5학년 76명, 그리고 6학년 77명이 각각 연구에 참여하였다(Table 1). 각종 검사는 2009년 4월부터 2010 년 2월까지 10 개월 동안 해당 학생이 소속된 유치원 및 초등학교의 조용한 공간에서 개별적으로 실시되었다.

Table 1. Participants' characteristics

\begin{tabular}{lcl}
\hline School level & Age/grade & $\mathrm{N}$ \\
\hline Kindergarten & 5-year-old & 32 \\
Elementary & 6-year-old & 45 \\
& Grade 1 & 72 \\
& Grade 2 & 70 \\
Grade 3 & 80 \\
Grade 4 & 70 \\
Grade 5 & 76 \\
Grade 6 & 77
\end{tabular}

\section{검사 도구}

\section{단어인지 검사}

40 개의 단어가 한 세트로 구성된 5 개 유형의 단어인지 하위 검사 를 실시하였다. 각 하위 검사는 고빈도 음운변동 의미 단어(예: 목요 일, 같이), 저빈도 규칙 의미 단어(예: 변질되다, 관념), 저빈도 음운 변동 의미 단어(예: 속박하다, 단련된), 무의미 규칙 단어(예: 모류하 다, 포순), 그리고 무의미 음운변동 단어(예: 뭅다, 개즘않이)로 구성 되었다(Appendix 1). 학생에게 주어진 단어를 읽도록 하였고, 정확 하게 읽은 경우 1 점, 그렇지 않으면 0 점으로 채점하여 총점은 각 세 트별 40점으로 점수를 산출하였다. 단어인지 검사의 내적 일관성 지수(Cronbach $\alpha$ 계수)는 .943으로 나타났다.

\section{읽기유창성 검사}

연구자가 개발한 검사로 가독성(readability), 어휘 친숙도, 선행 지식 통제 등을 고려하여 각 연령별 전래동화 지문을 개발한 후, 학 생이 1 분 동안 빠르게 소리 내어 읽도록 하여 읽기유창성을 측정하 였다(Appendix 2). 1 분 동안 읽은 전체 어절 수에서 정확하게 읽지 않은 어절 수를 빼서 읽기유창성 점수를 계산하였다.

\section{읽기이해 검사}

이야기글 읽기이해 검사

읽기유창성 검사와 동일한 지문을 활용하여 읽기이해 검사를 실 시하였다(Appendix 2). 학생이 전래동화를 읽고 물음에 답하는 형 식으로 이루어졌다. 읽기이해 문항은 인물이나 배경에 대한 간단한 내용 지식을 묻는 문항, 사건에 대한 이해 지식을 묻는 문항, 지문의 내용을 바탕으로 추론하는 문항 등 총 7문항으로 구성하였다. 읽기 이해 검사의 내적 일관성 지수(Cronbach $\alpha$ 계수)는 .815로 나타났 으며, KISE 기초학력검사-짧은 글 이해 검사와의 상관으로 산출한 공인 타당도는 .581 로 양호하게 나타났다.

\section{KISE 기초학력검사(KISE-BAAT)-짧은 글 이해 검사}

표준화 검사인 KISE-BAAT (Park, Kim, Song, Jung, \& Jung, 2008) 중, 짧은 글이해 소검사를 실시하여 읽기이해력을 측정하였다. KISEBAAT-짧은 글 이해 검사는 문장을 읽고 주요 사실에 답하기, 사실 과 느낌, 의견 구분하기, 비유나 상징적 표현 이해하기, 설명글을 읽 고 중심내용 파악하기, 결과 유추하기, 비판하기 등 30 문항으로 구 성되어 있다. 검사는 시간제한 없이 실시되었으며, 연속적으로 5 문 항에 대해 오반응을 하면 이를 중지점으로 보아 검사를 종료하였 다. KISE-BAAT-짧은 글 이해 검사는 총 30점 만점으로 구성되어 있다. KISE-BAAT-짧은 글 이해 검사의 내적 일관성 지수(Cron- 
bach $\alpha$ 계수)는 .810으로 나타났다.

\section{확인적 요인 분석(Confirmatory Factor Analysis, CFA)}

본 연구에서는 읽기 구조에 관한 세 가지 가설 중 어떠한 요인 구 조가 읽기 구조를 설명하는데 가장 적합한지 알아보고, 연령별로 차별적 특징이 존재하는지 살펴보기 위해 AMOS v21.0 프로그램 을 사용하여 확인적 요인 분석을 실시하였다.

가설1: 단어인지, 읽기유창성, 읽기이해가 각각 별개 요인 가설2: 읽기유창성은 단어인지와같은 요인, 읽기이해는 별개 요인 가설3: 단어인지는 별개 요인, 읽기이해와 읽기유창성은 같은 요인

본 연구에서는 유창성 요인의 잠재변수(latent variable)에 대한 측정변수(observed variable)가 한 개인 관계로, 신뢰도 값의 추정 치를 .8 로 간주하며, .8 의 제곱근의 값인 .8944 를 잠재변수와 측정 변수 간 경로의 분산에 지정하였다. 또한, 1 -신뢰도 값인 .2를 측정 변수의 오차항의 분산에 지정한 후, 결과를 분석하였다(Woo, 2012).

모형의 해석 및 적합도 검증을 위한 기준으로 $\chi^{2}$ 과 표준카이자 승(normed chi-square, NC)을 사용하고, 절대적합지수 RMSEA를 활용하며, 증분적합지수의 NFI, TLI 및 CFI를 활용하였다. $\chi^{2}$ 은 표 본의 크기에 민감하고 표본의 크기가 커질수록 부적합하게 나타날 수 있으므로, $\mathrm{NC}$ 값을 추가적으로 살펴보았고, $\mathrm{NC}$ 값이 얼마가 되 어야 모델이 적합한 것으로 판단할 수 있는지에 대한 명확한 기준은 없으며, 일반적으로 $\mathrm{NC}<3.0$ 이면 양호한 것으로 판단한다(Wheaton, Muthen, Alwin, \& Summers, 1977; as cited in Kim, 2010). 또 한, 전체 표본수에 민감하지 않은 TLI (NNFI)를 보조 지표로 활용 하였다. RMSEA는 1 보다 작을수록, NFI, TLI 및 CFI는 1 에 가까울 수록 모형 적합도(model fit)가 좋다고 해석할 수 있으며, .9보다 큰 경우 아주 좋은 모형 적합도로 설명할 수 있다(Moon, 2009). 전체 다섯 가지 지표 중에서 가장 좋은 적합도 기준에 충족하는 지표가 많을수록 해당 연령 혹은 학년의 읽기 구조를 나타내는 적절한 가 설로 해석하였다.

\section{연구 결과}

\section{기술 통계}

학년별 검사도구 측정 결과에 대한 기술통계 결과(descriptive analysis)는 Tables 2-4와 같다. 또한 본 연구에 사용된 소검사에 대 하여 확인적 요인 분석을 실행하기에 앞서 정규분포에 대한 가정을 검증하기 위하여 첨도와왜도를 검토하였다. 변인 간의 다중공선성 이 존재하는지를 살펴본 결과 VIF값이 4 를 넘지 않는 것으로 나타
Table 2. Descriptive analysis on word recognition test across ages/grades

\begin{tabular}{|c|c|c|c|c|c|}
\hline Age/grade & $\begin{array}{l}\text { Word recogni- } \\
\text { tion test }\end{array}$ & Mean & SD & Min. & Max. \\
\hline \multirow{5}{*}{$\begin{array}{c}\text { 5-year-old } \\
(\mathrm{N}=32)\end{array}$} & 1 & 26.031 & 10.971 & 1 & 39 \\
\hline & 2 & 24.875 & 9.912 & 4 & 39 \\
\hline & 3 & 13.375 & 8.590 & 0 & 31 \\
\hline & 4 & 25.500 & 10.454 & 3 & 40 \\
\hline & 5 & 12.344 & 8.446 & 0 & 29 \\
\hline \multirow{5}{*}{$\begin{array}{l}\text { 6-year-old } \\
(\mathrm{N}=45)\end{array}$} & 1 & 32.244 & 9.286 & 0 & 39 \\
\hline & 2 & 28.511 & 10.242 & 2 & 40 \\
\hline & 3 & 18.444 & 9.270 & 0 & 36 \\
\hline & 4 & 29.067 & 9.146 & 2 & 39 \\
\hline & 5 & 17.378 & 8.677 & 0 & 34 \\
\hline \multirow{5}{*}{$\begin{array}{l}\text { Grade } 1 \\
\qquad(\mathrm{~N}=72)\end{array}$} & 1 & 35.181 & 6.177 & 13 & 45 \\
\hline & 2 & 31.750 & 6.984 & 11 & 45 \\
\hline & 3 & 21.861 & 8.247 & 3 & 37 \\
\hline & 4 & 32.056 & 7.146 & 10 & 45 \\
\hline & 5 & 21.597 & 8.815 & 4 & 36 \\
\hline \multirow{5}{*}{$\begin{array}{l}\text { Grade } 2 \\
\qquad(\mathrm{~N}=70)\end{array}$} & 1 & 38.043 & 3.850 & 28 & 45 \\
\hline & 2 & 34.371 & 4.216 & 22 & 40 \\
\hline & 3 & 25.400 & 7.014 & 9 & 38 \\
\hline & 4 & 34.471 & 4.791 & 22 & 45 \\
\hline & 5 & 24.500 & 6.565 & 10 & 37 \\
\hline \multirow{5}{*}{$\begin{array}{l}\text { Grade } 3 \\
\qquad(\mathrm{~N}=80)\end{array}$} & 1 & 39,038 & 2.674 & 32 & 45 \\
\hline & 2 & 37.038 & 3.392 & 25 & 42 \\
\hline & 3 & 29.975 & 5.857 & 14 & 42 \\
\hline & 4 & 36.175 & 4.409 & 21 & 44 \\
\hline & 5 & 27.313 & 5.435 & 11 & 37 \\
\hline \multirow{5}{*}{$\begin{array}{l}\text { Grade } 4 \\
\qquad(\mathrm{~N}=70)\end{array}$} & 1 & 38.732 & 3.529 & 34 & 45 \\
\hline & 2 & 37.577 & 4.857 & 30 & 40 \\
\hline & 3 & 30.775 & 6.547 & 16 & 40 \\
\hline & 4 & 36.549 & 5.505 & 22 & 44 \\
\hline & 5 & 28.549 & 6.261 & 13 & 40 \\
\hline \multirow{5}{*}{$\begin{array}{l}\text { Grade } 5 \\
\qquad(\mathrm{~N}=76)\end{array}$} & 1 & 39.566 & 2.858 & 31 & 45 \\
\hline & 2 & 37.408 & 4.215 & 16 & 42 \\
\hline & 3 & 32.066 & 6.846 & 7 & 45 \\
\hline & 4 & 37.934 & 5.068 & 13 & 45 \\
\hline & 5 & 28.421 & 5.956 & 6 & 38 \\
\hline \multirow{5}{*}{$\begin{array}{l}\text { Grade } 6 \\
(\mathrm{~N}=77)\end{array}$} & 1 & 38.623 & 0.779 & 34 & 39 \\
\hline & 2 & 38.805 & 1.505 & 32 & 40 \\
\hline & 3 & 33.104 & 4.294 & 18 & 40 \\
\hline & 4 & 37.675 & 2.042 & 32 & 40 \\
\hline & 5 & 30.416 & 4.200 & 19 & 38 \\
\hline
\end{tabular}

나 다중공선성에는 문제가 없는 것으로 나타났다.

Table 2에는 단어인지 검사에 대한 연령 및 학년별 평균, 표준편 차, 최소값과 최대값이 제시되었다. 만 5 세의 경우, 단어인지 검사별 평균 점수는 12.34 점에서 26.03점으로 나타났고, 만 6세의 경우 17.38 에서 32.24점으로 나타났다. 초등학교 1학년부터 6학년까지 
Table 3. Descriptive analysis on reading fluency test across ages/grades

\begin{tabular}{lcccc}
\hline Age/grade & Mean & SD & Min. & Max. \\
\hline 5-year-old & 34.844 & 18.960 & 2 & 80 \\
6-year-old & 56.933 & 23.704 & 1 & 97 \\
Grade 1 & 69.250 & 20.672 & 26 & 130 \\
Grade 2 & 76.857 & 18.246 & 38 & 109 \\
Grade 3 & 86.600 & 16.224 & 47 & 135 \\
Grade 4 & 92.186 & 18.642 & 35 & 132 \\
Grade 5 & 91.289 & 18.385 & 47 & 133 \\
Grade 6 & 101.896 & 19.884 & 37 & 151 \\
\hline
\end{tabular}

Table 4. Descriptive analysis on reading comprehension test across ages/grades

\begin{tabular}{llrrrr}
\hline Age/grade & $\begin{array}{c}\text { Reading comprehension } \\
\text { test }\end{array}$ & Mean & SD & Min. & Max. \\
\hline 5-year-old & Researcher-developed & 1.129 & 1.408 & 0 & 6 \\
& KISE-BAAT & 2.375 & 2.485 & 0 & 10 \\
6-year-old & Researcher-developed & 2.933 & 2.250 & 0 & 7 \\
& KISE-BAAT & 5.200 & 3.468 & 0 & 15 \\
Grade 1 & Researcher-developed & 3.833 & 1.979 & 0 & 7 \\
& KISE-BAAT & 6.694 & 3.479 & 0 & 16 \\
Grade 2 & Researcher-developed & 3.571 & 1.699 & 0 & 7 \\
& KISE-BAAT & 8.343 & 4.681 & 0 & 20 \\
Grade 3 & Researcher-developed & 4.038 & 2.674 & 1 & 7 \\
& KISE-BAAT & 12.288 & 5.764 & 0 & 27 \\
Grade 4 & Researcher-developed & 5.357 & 1.494 & 1 & 7 \\
& KISE-BAAT & 17.254 & 6.405 & 0 & 28 \\
Grade 5 & Researcher-developed & 3.105 & 2.024 & 0 & 6 \\
& KISE-BAAT & 18.237 & 6.749 & 0 & 28 \\
Grade 6 & Researcher-developed & 4.234 & 1.356 & 1 & 7 \\
& KISE-BAAT & 20.675 & 4.471 & 7 & 29 \\
\hline
\end{tabular}

KISE-BAAT = Korea Institute for Special Education-Basic Academic Achievement Test.

의 단어인지 검사의 평균 점수는 각각 21.6점-35.18점, 24.5점-8.04 점, 27.31점-39.04점, 28.55점-38.73점, 28.42점-39.57점, 30.42점-38.81 점으로 나타났다.

또한, Table 3에는 읽기유창성 검사에 대한 연령 및 학년별 평균, 표준편차, 최소값과 최대값을 각각 제시하였다. 유창성 검사 결과, 만 5 세의 경우 유창성 검사 점수의 평균이 34.844 어절로 나타났 고, 만 6 세의 경우 56.933 어절, 1 학년 69.250 어절, 2 학년 76.857 어 절, 3학년 86.600 어절, 4 학년 92.186 어절, 5 학년 91.289 어절, 그리 고 6학년 101.896 어절로 나타났다.

Table 4에는 연구자가 개발한 읽기이해 검사인 전래동화 검사와 표준화 검사인 KISE-BAAT의 연령별(학년별) 평균과 표준편차, 최 소값과 최대값을 제시하였다. 만 5 세는 전래동화 검사에서 평균 1.129점, KISE-BAAT에서 평균 2.375점을 나타냈고, 만 6세는 전래 동화 검사에서 평균 2.933점, KISE-BAAT에서 평균 5.200점을 나
Table 5. Result of confirmatory factor analysis across hypothesis

\begin{tabular}{lcccccc}
\hline Hypothesis & $\chi^{2}$ & $\chi^{2} / \mathrm{df}$ & NFI & TLI & CFI & RMSEA \\
\hline Hypothesis 1 & 13.389 & 1.488 & .996 & .996 & .999 & .030 \\
Hypothesis 2 & 46.816 & 4.682 & .987 & .971 & .990 & .083 \\
Hypothesis 3 & 74.395 & 5.723 & .979 & .963 & .983 & .094
\end{tabular}

Bold indicates the best-fitting model.

$\mathrm{NFI}=$ normal fit index; $\mathrm{TLI}=$ TuckerLewis index; $\mathrm{CFI}=$ goodness-of-fit index; RMSEA= root mean square error of approximation.

타냈다. 1 학년의 전래동화 검사와 KISE-BAAT 검사의 평균은 각각 3.833점, 6.694점, 2 학년의 경우 각각 3.571점, 8.343점, 3학년의 경우 각각 4.038점, 12.288 점, 4 학년의 경우 5.357점, 17.254 점으로 나타 났다. 5 학년은 전래동화 검사에서 평균 3.105점, KISE-BAAT에서 평균 18.237점, 6학년의 경우 전래동화 검사에서 평균 4.234점, KISEBAAT에서 평균 20.675점으로 나타났다.

\section{전체 확인적 요인 분석 결과}

만 5세부터 초등학교 6학년까지 총 522명을 대상으로 세 가지 가 설에 대한 확인적 요인분석을 실시한 결과는 Table 5 와 같다. 단어 인지, 읽기유창성, 읽기이해가 각각 개별 요인이라는 가설1이 가장 적합한 모델로 나타났다 $\left(\chi^{2}=13.389, \mathrm{NFI}=.996, \mathrm{TLI}=.996, \mathrm{CFI}=\right.$ .999, RMSEA=.030).

\section{연령별 확인적 요인 분석 결과}

연령별로 읽기유창성이 별개의 요인으로 읽기를 설명하는지를 살펴본 결과는 Table 6과 같다. 만 5 세와 만 6 세는 읽기유창성이 단 어인지와 하나의 요인으로 묶이는 가설2가 가장 좋은 모델인 것으 로 나타났다 (만 5세: $\chi^{2}=29.942, \mathrm{NFI}=.932, \mathrm{TLI}=.945, \mathrm{CFI}=.971$, RMSEA $=.126$; 만 6 세: $\chi^{2}=20.157, \mathrm{NFI}=.950, \mathrm{TLI}=.986, \mathrm{CFI}=992$, RMSEA $=.065)$. 이에 비해 초등학교 1학년부터 6학년까지는 단어 인지, 읽기유창성, 읽기이해가 각각 독립적인 요인으로 읽기를 설명 한다는 가설1이 가장 적합한 모델로 나타났다(1학년: $\chi^{2}=23.261$, $\mathrm{NFI}=.947, \mathrm{TLI}=.947, \mathrm{CFI}=.975, \mathrm{RMSEA}=.105 ; 2$ 학년: $\chi^{2}=29.702$, $\mathrm{NFI}=.886, \mathrm{TLI}=.897, \mathrm{CFI}=.941, \mathrm{RMSEA}=.111 ; 3$ 학년: $\chi^{2}=19.495$, $\mathrm{NFI}=.924, \mathrm{TLI}=.973, \mathrm{CFI}=.985, \mathrm{RMSEA}=.053 ; 4$ 학년: $\chi^{2}=18.193$, $\mathrm{NFI}=.953, \mathrm{TLI}=.983, \mathrm{CFI}=.991, \mathrm{RMSEA}=.055 ; 5$ 학년: $\chi^{2}=14.095$, $\mathrm{NFI}=.962, \mathrm{TLI}=.993, \mathrm{CFI}=.997, \mathrm{RMSEA}=.034 ; 6$ 학년: $\chi^{2}=10.294$, $\mathrm{NFI}=.916, \mathrm{TLI}=1.105, \mathrm{CFI}=1.000$, $\mathrm{RMSEA}=.000$ ).

한편, 초등학교 1 학년부터 6 학년까지의 결과에서 가설2와 가설3 을 연령별로 비교하여 살펴보면, 초등학교 1학년부터 3학년까지는 읽기유창성이 단어인지와 하나의 요인으로 묶이는 가설2가 가설3 
Table 6. Result of confirmatory factor analysis across ages (grades)

\begin{tabular}{|c|c|c|c|c|c|c|c|}
\hline Age/grade & Hypothesis & $x^{2}$ & $\chi^{2} / \mathrm{df}$ & $\mathrm{NFI}$ & TLI & $\mathrm{CFI}$ & RMSEA \\
\hline \multirow[t]{3}{*}{ 5-year-old } & Hypothesis 1 & 42.137 & 2.634 & .885 & .864 & .922 & .197 \\
\hline & Hypothesis 2 & 29.942 & 1.663 & .932 & .945 & .971 & .126 \\
\hline & Hypothesis 3 & 42.174 & 2.481 & .884 & .877 & .925 & .188 \\
\hline \multirow[t]{3}{*}{ 6-year-old } & Hypothesis 1 & 19.922 & 1.245 & .951 & .982 & .990 & .075 \\
\hline & Hypothesis 2 & 20.157 & 1.186 & .950 & .986 & .992 & .065 \\
\hline & Hypothesis 3 & 23.386 & 1.376 & .942 & .972 & .983 & .092 \\
\hline \multirow[t]{3}{*}{ Grade 1} & Hypothesis 1 & 23.261 & 1.789 & .947 & .947 & .975 & .105 \\
\hline & Hypothesis 2 & 25.470 & 1.819 & .942 & .945 & .972 & .107 \\
\hline & Hypothesis 3 & 33.669 & 2.405 & .924 & .905 & .953 & .141 \\
\hline \multirow[t]{3}{*}{ Grade 2} & Hypothesis 1 & 29.702 & 1.856 & .886 & .897 & .941 & .111 \\
\hline & Hypothesis 2 & 34.091 & 2.005 & .869 & .879 & .926 & .121 \\
\hline & Hypothesis 3 & 35.018 & 2.060 & .865 & .872 & .922 & .124 \\
\hline \multirow[t]{3}{*}{ Grade 3} & Hypothesis 1 & 19.495 & 1.218 & .924 & .973 & .985 & .053 \\
\hline & Hypothesis 2 & 24.884 & 1.464 & .903 & .943 & .966 & .077 \\
\hline & Hypothesis 3 & 25.231 & 1.484 & .902 & .941 & .964 & .078 \\
\hline \multirow[t]{3}{*}{ Grade 4} & Hypothesis 1 & 18.193 & 1.213 & .953 & .983 & .991 & .055 \\
\hline & Hypothesis 2 & 25.232 & 1.577 & .935 & .955 & .974 & .091 \\
\hline & Hypothesis 3 & 21.403 & 1.338 & .945 & .974 & .985 & .069 \\
\hline \multirow[t]{3}{*}{ Grade 5} & Hypothesis 1 & 14.095 & 1.084 & .962 & .993 & .997 & .034 \\
\hline & Hypothesis 2 & 18.534 & 1.544 & .951 & .956 & .981 & .085 \\
\hline & Hypothesis 3 & 19.193 & 1.371 & .949 & .970 & .985 & .070 \\
\hline \multirow[t]{3}{*}{ Grade 6} & Hypothesis 1 & 10.294 & .643 & .916 & 1.105 & 1.000 & .000 \\
\hline & Hypothesis 2 & 18.254 & 1.074 & .851 & .978 & .987 & .031 \\
\hline & Hypothesis 3 & 15.515 & .913 & .874 & 1.026 & 1.000 & .000 \\
\hline
\end{tabular}

Bold indicates the best-fitting model.

$\mathrm{NFI}=$ normal fit index; $\mathrm{TLI}=$ TuckerLewis index; $\mathrm{CFI}=$ goodness-of-fit index; RMSEA= root mean square error of approximation.

보다 적합한 모델로 나타났다. 그에 비해 초등학교 4학년부터 6학 년까지는 읽기이해가 읽기유창성과 하나의 요인으로 묶이는 가설3 이 가설2보다 더 적합한 모델로 나타났다.

\section{논의 및 결론}

초기 읽기 연구에서는 읽기를 단어인지와 읽기이해로 구성된 개 념으로 보았지만(Hoover \& Gough, 1990), 지난 20여 년간의 연구 를 통해 읽기는 단어인지와 읽기이해 이외에 읽기유창성을 포함하 는 것으로 재개념화 되었다(예: Bashir \& Hook, 2009; MacArthur, Konold, Glutting \& Alamprese, 2010; Speece et al., 2010). 이를 반 영하듯, 읽기장애(reading disabilities)는 단어인지 읽기장애(reading disability: word recognition), 유창성 읽기장애(reading disability: fluency), 이해 읽기장애(reading disability: comprehension)로 분류된다(Flanagan, Ortiz, Alfonso, \& Mascolo, 2002; Fletcher et al., 2002). 이러한 연구 결과는 미국특수교육법에도 반영되어 2004 년 이후로 읽기유창성 장애가 읽기장애의 하위 유형으로 구분되기
시작하였고, National Reading Panel (2000)은 “읽기를 아동에게 가르치기(Teaching children to read)"라는 제목으로 성공적인 읽 기를 위해 반드시 고려해야 할 다섯 가지 영역 중 읽기유창성을 한 영역으로 포함하였다.

본 연구에서는 한글을 사용하는 국내 아동들을 대상으로 읽기 구조에 대한 연구를 실시함으로써, 단어인지, 읽기유창성, 읽기이 해로 구성된 3요인 읽기 구조가 국내에서도 적용되는지를 살펴보 고자 하였다. 이를 위해 본 연구에서는 한글 읽기를 시작하는 시점 인 만 5세부터 초등학교 6학년 학생을 대상으로 읽기유창성이 단 어인지와 읽기이해와 더불어 독립적인 읽기 구조를 구성하고 있는 지를 살펴보고, 이러한 읽기 구조의 양상에 있어 연령별(학년별)로 특징적 차이가 나타나는지를 살펴보고자 하였다. 본 연구의 결과 를 요약하면 다음과 같다.

첫째, 전체 아동을 대상으로 실시한 결과, 단어인지, 읽기유창성, 읽기이해로 구성된 3요인 읽기 구조가 가장 적합한 모델로 나타났 다. 둘째, 연령별 분석 결과를 살펴보면, 취학 전 아동의 경우와 초 등학교 학생의 결과가 다소 차별화되는 것으로 나타났다. 취학 전 
인 만 5 세와 만 6 세의 경우에는 단어인지와 읽기유창성은 하나의 요인으로 읽기이해와 구분되는 모델, 즉 2 요인 읽기 구조가 가장 적 합한 모델로 나타났다. 그 후 초등학교 1학년-6학년의 경우 읽기유 창성은 단어인지, 읽기이해와는 별개의 요인으로 분화되어 읽기를 설명하는 독립적인 요인으로 나타난 것을 알 수 있다. 구체적으로 살펴보면, 초등학교 1학년부터 6학년까지는 단어인지, 읽기유창성, 읽기이해로 구성된 3 요인 읽기 구조가 가장 적합한 모델인 것으로 나타났다. 이러한 결과를 종합해 볼 때, 취학 전 아동의 읽기 구조 와 초등학생의 읽기 구조가 차별적으로 나타난다는 것을 알 수 있 다. 즉, 취학 전 아동의 경우에는 초기 읽기가 발달하는 단계로 개 별 단어의 음독에 초점이 맞춰진 단계이며, 이 단계에서는 '글' 수 준에서의 읽기유창성 보다는 '개별 단어' 수준에서의 정확성이 중 요한 시기이다. 따라서 이 시기에는 단어인지와 읽기유창성이 단일 요인으로 묶이는 것으로 보인다. 그에 비해 초등학교 1학년 이후에 는 읽기유창성이 독립적인 요인으로 분화되어 나타났는데, 이는 초 등학교 1학년 이후에는 '개별 단어' 수준에서의 정확성 이상의 읽 기 처리 능력이 발달하는 시기라고 해석해 볼 수 있을 것이다. 이러 한 연구 결과는 읽기 발달 단계가 높아지면서 읽기유창성이 독립적 인 요인으로 분화된다는 선행연구 결과와 맥을 같이 하기는 하지 만, 국내 아동의 경우에는 초등학교 4학년 시점이 아닌 초등학교 1 학년 때부터 읽기유창성이 별개의 요인으로 나타났다는 점에서 차 별성을 지닌다고 할 수 있다. 또한, 이러한 연구 결과의 차이는 영어 와 비교하였을 때, 표층표기체계 언어로서의 성격을 더 지닌 한글 의 특성상 단어인지 숙달의 정도가 영어에 비해 빠르기 때문으로 해석해 볼 수 있을 것이다(Kim, Choi, Jung, \& Kim, 2012; Ellis \& Hooper, 2001; Goswami, Gombert, \& De Barrera, 1998). 이미 초 등학교 저학년 때 단어인지 정확도에 있어 천정효과가 나타난다고 보고한 표층표기체계 언어권에서의 선행연구(Cossu et al., 1995; Landerl \& Wimmer, 2008)와 관련지어볼 때, 한글을 사용하는 아 동의 경우에도 초등학교 1 학년 때부터 '개발 단어' 읽기 이상의 읽 기 능력이 발달하게 된다고 해석해 볼 수 있을 것이다.

한편, 한 가지 더 주목할 만한 점은 연령별 읽기 요인 구조를 설명 하기에 가장 적합성이 높은 가설 1 을 제외하고 가설 2 와 가설 3 의 결과를 비교해보면, 초등학교 1학년부터 3학년까지는 가설 2 가 가 설 3보다 적합한 모델로 나타난 반면, 초등학교 4학년부터 6학년까 지는 가설 3 이 가설 2 보다 더 적합한 모델로 나타났다는 점이다. 이 러한 결과는 한글의 표층표기체계 언어로서의 성격으로 인하여 3 요인 읽기 구조가 초등학교 1학년 때부터 가장 타당한 모델로 나타 나기는 하였지만, 초등학교 저학년의 경우에는 단어인지와 읽기유 창성이 좀 더 관련성을 지니고, 초등학교 고학년의 경우에는 읽기
유창성과 읽기이해가 좀 더 관련성을 지니는 것을 알 수 있다. 이러 한 연구 결과는 초등학교 1학년 때부터 읽기유창성이 독립적인 요 인으로 분화되기는 하지만, 초등학교 저학년 때는 단어인지와 읽기 유창성의 관련성이 상대적으로 더 높은 반면, 초등학교 고학년 때 는 읽기유창성과 읽기이해의 관련성이 상대적으로 더 높은 것으로 해석해볼수 있을 것이다.

아울러, 본 연구는 읽기 요인의 발달적 패턴에 대한 의미 있는 결 과를 제시하고 있지만, 만 5 세와 6 세는 읽기 발달 특성상 $\mathrm{SD}$ 가 커 서 다소 RMSEA가 높았던 점을 주의해야 할 것이다. 또한, 본 연구 에서 사용된 읽기유창성 검사는 글(text) 수준에서의 유창성을 측 정한 것이므로, 본 연구의 결과를 토대로 단어나 문장 수준에서의 읽기유창성 검사로의 확장을 통해 좀 더 포괄적인 범위에서 읽기유 창성의 읽기 구조에서의 역할에 대한 분석이 필요할 것이다.

\section{REFERENCES}

Bashir, A. S., \& Hook, P. E. (2009). Fluency: a key link between word identification and comprehension. Language, Speech, and Hearing Services in Schools, 40, 196-200.

Berninger, V. W., Abbott, R. D., Billingsley, F., \& Nagy, W. (2001). Processes underlying timing and fluency of reading: efficiency, automaticity, coordination, and morphological awareness. In M. Wolf (Ed.), Dyslexia, fluency, and the brain (pp. 383-414). Timonium, MD: York Press.

Breznitz, Z. (2006). Fluency in reading: synchronization of processes. Mahwah, NJ: Lawrence Erlbaum Associates.

Carr, T. H., \& Levy, B. A. (1990). Reading and its development: component skills approaches. San Diego, CA: Academic Press.

Chall, J. S. (1983). Learning to read: the great debate. New York, NY: McGrawHill.

Cossu, G., Giuliotta, M., \& Marshall, J. C. (1995). Acquisition of reading and written spelling in a transparent orthography: two non-parallel processes? Reading and Writing, 7, 9-22.

Ellis, N. C., \& Hooper, A. M. (2001). Why learning to read is easier in Welsh than in English: orthographic transparency effects evinced with frequency-matched tests. Applied Psycholinguistics, 22, 571-599.

Flanagan, D. P., Ortiz, S. O., Alfonso, V. C., \& Mascolo, J. T. (2002). The achievement test desk reference (ATDR): comprehensive assessment and learning disabilities. Boston, MA: Allyn \& Bacon.

Fletcher, J. M., Lyon, G. R., Barnes, M., Stuebing, K. K., Francis, D. J., Olson, R. K., ... \& Shaywitz, B. A. (2001). Classification of learning disabilities: an 
evidence-based evaluation. In R. Bradley et al. (Eds.), Identification of learning disabilities: research to practice (pp. 185-250). Mahwah, NJ: Lawrence Erlbaum Associates.

Fuchs, L. S., Fuchs, D., Hosp, M. K., \& Jenkins, J. R. (2001). Oral reading fluency as an indicator of reading competence: a theoretical, empirical, and historical analysis. Scientific Studies of Reading, 5, 239-256.

Geva, E., \& Farnia, F. (2012). Developmental changes in the nature of language proficiency and reading fluency paint a more complex view of reading comprehension in ELL and EL1. Reading and Writing, 25, 1819-1845.

Goswami, U., Gombert, J. E., \& de Barrera, L. F. (1998). Children’s orthographic representations and linguistic transparency: nonsense word reading in English, French, and Spanish. Applied Psycholinguistics, 19, 19-52.

Gough, A. (2002). Mutualism: a different agenda for environmental and science education. International Journal of Science Education, 24, 1201-1215.

Gough, P. B., \& Tunmer, W. E. (1986). Decoding, reading, and reading disability. Remedial and Special Education, 7, 6-10.

Hoover, W. A., \& Gough, P. B. (1990). The simple view of reading. Reading and Writing, 2, 127-160.

Kim, A. H., \& Kim, U. J. (2015). A longitudinal study on prediction of word recognition, reading fluency, and reading comprehension of 4-year-old children. Special Education \& Rehabilitation Science, 54, 45-70.

Kim, A. H., Choi, K. S., Jung, H. S., \& Kim, M. J. (2012). A comparison of elementary students with reading disabilities to students without disabilities on word recognition accuracy and speed. Korean Journal of Communication Disorders, 17, 508-519.

Kim, A. H., Kim, U. J., Yoo, H. S., \& Hwang, M. (2011). Reliability and validity of a test of reading achievement and reading psychological processes: focusing on Gyeonggi-do and Chungcheongnam-do. Korean Journal of Communication Disorders, 16, 276-294.

Landerl, K., \& Wimmer, H. (2008). Development of word reading fluency and spelling in a consistent orthography: an 8-year follow-up. Journal of Educational Psychology, 100, 150-161.

Lee, I. H., \& Kim, D. I. (2003). The relationship between reading fluency and reading comprehension in primary grades. Journal of Educational Psychology, 17, 1-24.

Lyon, G. R., \& Moats, L. C. (1997). Critical conceptual and methodological considerations in reading intervention research. Journal of Learning Disabilities, 30, 578-588.

MacArthur, C. A., Konold, T. R., Glutting, J. J., \& Alamprese, J. A. (2010). Reading component skills of learners in adult basic education. Journal of Learning Disabilities, 43, 108-121.

Moon, S. B. (2009). Basic concepts and applications of structural equation modeling: with AMOS 17.0. Seoul: Hakjisa.

National Reading Panel. (2000). Teaching children to read: an evidence-based assessment of the scientific research literature on reading and its implications for reading instruction. Washington, DC: National Institute of Child Health and Human Development, National Institutes of Health.

Park, G., Kim, G., Song, Y., Jung, D., \& Jung, I. (2008). Korea Institute for Special Education-Basic Academic Achievement Test (KISE-BATT). Ansan; Korea Institute for Special Education.

Seymour, P., Aro, M. \& Erskine, J. M. (2003). Foundation literacy acquisition in European languages. British Journal of Psychology, 94, 143-174.

Silverman, R. D., Speece, D. L., Harring, J. R., \& Ritchey, K. D. (2013). Fluency has a role in the simple view of reading. Scientific Studies of Reading, 17, 108-133.

Speece, D. L., Ritchey, K. D., Silverman, R., Schatschneider, C., Walker, C. Y., \& Andrusik, K. N. (2010). Identifying children in middle childhood who are at risk for reading problems. School Psychology Review, 39, 258-276.

Tilstra, J., McMaster, K., Van den Broek, P., Kendeou, P., \& Rapp, D. (2009). Simple but complex: components of the simple view of reading across grade levels. Journal of Research in Reading, 32, 383-401.

Wheaton, B., Muthen, B., Alwin, D. F., \& Summers, G. F. (1977). Assessing reliability and stability in panel models. Sociological methodology, 8, 84136.

Wolf, M., \& Katzir-Cohen, T. (2001). Reading fluency and its intervention. Scientific Studies of Reading, 5, 211-239.

Woo, J. P. (2012). Concepts and understanding of structural equation modeling. Seoul: Hannarae Publishing.

Wood, D. E. (2006). Modeling the relationship between oral reading fluency and performance on a statewide reading test. Educational Assessment, 11, 85-104. 
Appendix 1. 본 연구에 사용된 단어인지 검사의 예시

\begin{tabular}{|c|c|c|c|c|}
\hline \multicolumn{5}{|c|}{ 1. 고빈도 음운변동 의미 단어 검사 } \\
\hline 목요일 & 줄넘기 & 붙이다 & 죽는 & 웃는 \\
\hline \multicolumn{5}{|c|}{ 2. 저빈도 규칙 의미 단어 검사 } \\
\hline 변질되다 & 사례금 & 영역 & 유독 & 의결하다 \\
\hline \multicolumn{5}{|c|}{ 3. 저빈도 음운변동 의미 단어 검사 } \\
\hline 속박하다 & 집행하다 & 선량하다 & 만용 & 관람료 \\
\hline \multicolumn{5}{|c|}{ 4. 무의미 규칙 단어 검사 } \\
\hline 모류하다 & 움돈 & 관멍하다 & 단하다 & 부내다 \\
\hline \multicolumn{5}{|c|}{ 5. 무의미 음운변동 단어 검사 } \\
\hline 뭅다 & 믹찹히 & 겅력 & 드넣지만 & 늑해 \\
\hline
\end{tabular}


Appendix 2. 본 연구에 사용된 읽기유창성 및 읽기이해 검사의 예시

\section{[읽기유창성 및 읽기이해 검사 지문]}

\section{제목: 사람을 구한 쥐}

옛날 호랑이가 담배 피던 시절이었지. 어느 산마을에 오막살이가 하나 있었어. 그 집에는 할아버지, 할머니, 아버지, 어머니, 아이들 일곱, 모두 열한 식구가 살았어. 비록 넉넉하지는 않았지만 열심히 농사를 지었지. 농사를 지어 거둔 곡식을 곳간에 두었어. 그런데 쥐들이 모여들어 몰래 먹지 뭐야. 다른 집들은 쥐를 잡으려고 야단이었지. 그런데 이 집은 쥐들을 그냥 두었어. 저것들도 살려는데 어찌 죽이나 하면서 말이야. 그래서 이 집에는 쥐가 많았지.

어느 여름에 큰 장마가 왔어. 산사태가 나고 홍수가 나고 난리였어. 하루는 식구들이 모두 점심을 먹었지. 그런데 갑자기 이상한 일이 일어났어. 곳간에 있던 쥐들이 마당으로 모였어. 한 쥐 위에 다른 쥐가 탔어. 그리고 그 위에 또 다른 쥐가 탔지. 이렇게 쥐들이 목말을 타고 밖으로 나갔어. 식구들은 너무 신기해서 우 르르 따라갔지. 그 사이에 뒷산이 무너졌어. 그래서 집이 흘더미에 깔려 망가졌지. 식구들은 쥐들 덕분에 목숨을 구했어. 쥐들도 착한 사람에게는 은혜를 갚았 던 거야.

\section{[읽기이해 질문]}

1. 이야기에 나오는 등장인물은 누구누구인가요?

2. 언제, 어디에서 있었던 일인가요?

3. 사람들이 왜 쥐를 잡으려고 하였나요?

4. 여름에 이 마을에서 어떤 일이 일어났나요?

5. 쥐들은 어떻게 밖으로 나갔나요?

6. 쥐들이 식구를 어떻게 구하였나요?

7. 식구는 쥐에게 어떤 마음을 가지게 되었을까요? 그것을 어떻게 알 수 있는지 글에서 찾아서 애기해 줄래요? 


\title{
국문초록
}

\section{확인적 요인 분석을 활용한 연령별 읽기 구조에 대한 연구}

\author{
김애화 ${ }^{1}$ 김의정 2 강은영
}

'단국대학교 특수교육과, ${ }^{2}$ 나사렛대학교 특수교육과, ${ }^{3}$ 용인대학교 교육대학원

배경 및 목적: 본 연구에서는 읽기 발달이 시작되는 만 5 세 아동부터 초등학교 6 학년 학생을 대상으로 읽기 구조를 살펴봄으로써, 읽 기 발달 단계에 따른 읽기 구조가 연령이 증가하면서 얼마나 일관성 있게 또는 차별적으로 나타나는지를 알아보고자 하였다. 방법: 연 령별 읽기 구조 분석을 위하여 확인적 요인 분석을 실시하였다. 결과: 전체 아동을 대상으로 분석을 실시한 결과, 3 요인 읽기 구조(단어 인지, 읽기유창성, 읽기이해가 별개의 요인)가 가장 적합한 모델로 나타났다. 하지만, 연령별 분석 결과를 살펴보면, 취학 전 아동인 만 5 세와 만 6 세의 경우에는 2요인 읽기 구조(단어인지와 읽기유창성은 같은 요인, 읽기이해는 별개 요인)가 가장 적합한 모델인 것으로 나 타났다. 이에 비해 초등학교 1 학년부터 6 학년까지는 3 요인 읽기 구조가 가장 적합한 모델로 나타났다. 논의 및 결론: 연구 결과에 근거 하여 볼 때 취학 전 아동의 경우와 초등학교 학생의 읽기 구조가 다소 차별화되는 것으로 나타났으며, 초등학교 1 학년 시점에서 읽기유 창성이 읽기 구조를 구성하는 별개의 요인으로 분리되는 것으로 나타났다.

핵심어: 단어인지, 읽기유창성, 읽기이해, 확인적 요인 분석, 읽기 구조

\section{참고문헌}

김계수(2010). 구조방정식 모형 분석. 서울, 한나래아카데미.

김애화, 김의정(2015). 만 4세 아동의 읽기 성취도에 대한 2년 종단 연구. 특수교육재활과학연구, 54, 45-70.

김애화, 김의정, 유현실, 황민아(2011). 읽기 성취 및 읽기 심리처리 검사의 신뢰도와 타당도에 관한 연구: 경기도와 충청남도 지역을 중심으로. 언어청

각장애연구, 16, 276-294.

김애화, 최경순, 정현승, 김민정(2012). 일반학생과 읽기장애학생의 단어인지 정확도 및 속도 특성 연구. 언어청각장애연구, 17, 508-519.

문수백 (2009). 구조방정식모델링의 이해와 적용. 서울: 학지사.

박경숙, 김계옥, 송영준, 정동영, 정인숙(2008). 기초학력검사(Korea Institute for Special Education-Basic Academic Achievement Test, KISE-BATT).

안산: 국립특수교육원.

우종필(2012). 구조방정식모델 개념과 이해. 서울, 한나래아카데미.

이일화, 김동일(2003). 읽기유창성과 독해력 수준과의 관계: 초등학교 저학년 학생을 중심으로. 교육심리연구, 17, 1-24. 